\title{
Differences in the Length and Thickness of the Coracoacromial Ligament between Normal Shoulders and Shoulders with Rotator Cuff Tears
}

\author{
Manabu Watanabe ${ }^{1 *}$, Hiroaki Kijima2,3, Takayuki Yoshikawa3 ${ }^{3}$, Kentaro Ohuchi' \\ Yusuke Sugimura ${ }^{3}$, Naohisa Miyakoshi², Yoichi Shimada ${ }^{2,3}$ \\ ${ }^{1}$ Department of Orthopedic Surgery, Yuri Kumiai General Hospital, Yuri-Honjo City, Japan \\ ${ }^{2}$ Department of Orthopedic Surgery, Akita University Graduate School of Medicine, Akita, Japan \\ ${ }^{3}$ Akita Sports, Arthroscopy, and Knee Group (ASAKG), Akita, Japan \\ Email: *scarecrowyugomusic.obfats@gmail.com
}

How to cite this paper: Watanabe, M., Kijima, H., Yoshikawa, T., Ohuchi, K., Sugimura, Y., Miyakoshi, N. and Shimada, Y. (2021) Differences in the Length and Thickness of the Coracoacromial Ligament between Normal Shoulders and Shoulders with Rotator Cuff Tears. Surgical Science, 12, 9-16.

https://doi.org/10.4236/ss.2021.121002

Received: January 4, 2021

Accepted: January 26, 2021

Published: January 29, 2021

Copyright $\odot 2021$ by author(s) and Scientific Research Publishing Inc. This work is licensed under the Creative Commons Attribution International License (CC BY 4.0).

http://creativecommons.org/licenses/by/4.0/

\begin{abstract}
Although the relationship between the material properties of the coracoacromial ligament and rotator cuff tears has been clarified, it is difficult to evaluate these properties in the clinical setting. The purpose of this study was to clarify the relationship between rotator cuff tears and the length and thickness of the coracoacromial ligament in living shoulders, in order to assess the potential use of these parameters as clinical indicators of the possible risk or progression of rotator cuff tears. Thirty-five volunteers (46 shoulders, mean age: 52 years) were enrolled. The presence or absence of rotator cuff tears and the length and thickness of the coracoacromial ligament were evaluated by ultrasonography. Longitudinal images of the coracoacromial ligaments with the acromion and coracoid process as landmarks were obtained, and the lengths of the ligaments were measured using acoustic shadows as the index. On the same screens, the thicknesses at the center of the ligaments were measured. Ligaments in shoulders with a rotator cuff tear were significantly shorter than ligaments in shoulders without a rotator cuff tear $(25.9 \pm$ $2.5 \mathrm{~mm}$ vs. $28.6 \pm 1.7 \mathrm{~mm}$, respectively; $\mathrm{P}<0.0001$ ). There was no significant difference in the thicknesses of the ligaments. The length and thickness of the coracoacromial ligament of living shoulders were easily evaluated with ultrasonography in the present study, and the coracoacromial ligament was found to be significantly shorter in shoulders with a rotator cuff tear. The risk and progression of rotator cuff tears can be evaluated clinically by measuring the length of the coracoacromial ligament.
\end{abstract}




\section{Keywords}

Coracoacromial Ligament, Rotator Cuff Tear, Shoulder, Subacromial

Impingement

\section{Introduction}

A rotator cuff tear is a common cause of shoulder pain and restricts shoulder range of motion; however, its cause remains unclear. Causes of rotator cuff tears are considered to include internal factors such as degeneration of the rotator cuff itself, and external factors such as impingement between the acromion and the rotator cuff. There are some reports of impingement between the cuff and the acromion [1] [2] [3], but there are few reports of contact between the cuff and the coracoacromial ligament, which also participates in so-called subacromial impingement.

The coracoacromial ligament contacts the rotator cuff physically when the shoulder joint is flexed, abducted, and extended [4]. In addition, we have reported that the degenerated coracoacromial ligament had a lower elastic modulus in an experiment using scanning acoustic microscopy that can evaluate the elasticity of biological tissues at the micro level [5]. From this result, we hypothesized that the tissue degeneration of the coracoacromial ligament progresses and the coracoacromial ligament hardens with age, thus increasing the contact pressure between the rotator cuff and the coracoacromial ligament. This may also be the reason for the increase in the proportion of older patients with shoulder pain or older patients with rotator cuff tears. Moreover, we have clarified the relationship between the elasticity of the coracoacromial ligament and rotator cuff tears by evaluating the elasticity of the coracoacromial ligament of the living shoulder with ultrasound elastography, which can non-invasively evaluate the amount of strain [6].

Evaluation of the material properties of the coracoacromial ligament requires the use of special devices, which are not widely used in clinical settings. Thus, the purpose of this study was to clarify the relationship between rotator cuff tears and the length and thickness of the coracoacromial ligament, which can be easily measured, in order to evaluate the potential use of these characteristics of the ligament as clinical indicators of the possible risk or progression of rotator cuff tears.

\section{Materials and Methods}

Of the new patients who visited 3 facilities within a certain period of time, those who had undergone shoulder ultrasound examination were included. In addition, healthy volunteers who visited the above 3 facilities during the same period and were undergoing rehabilitation for diseases other than shoulders were also included. However, those who had previously had shoulder surgery or shoulder 
trauma were excluded. A total of 46 shoulders of 35 persons with and without rotator cuff tears, with a mean age of 52 years (range: $11-83$ years), were enrolled. There were 19 male and 16 female shoulders (Table 1).

The presence or absence of rotator cuff tears and the length and thickness of the coracoacromial ligament were evaluated by ultrasonography (EUB-7500, HITACHI, Tokyo, Japan). The measurement accuracy of this device is very high because the minimum distance between 2 points that can be identified by this device is $0.1 \mathrm{~mm}$ or less. The shoulders without rotator cuff tears were defined as the Normal group (27 shoulders, mean age: 41 years), and the shoulders with rotator cuff tears were defined as the Cuff tear group (19 shoulders, mean age: 67 years) (Table 1). Rotator cuff tears were defined as complete ruptures of the supraspinatus or infraspinatus muscles. Tear size and shape were not recorded in this study. In the Normal group, those younger than 50 years of age were defined as the Young group (15 shoulders, mean age: 23 years), and those older than 50 years of age were defined as the Old group (12 shoulders, mean age: 64 years).

Longitudinal images of the coracoacromial ligaments with the coracoid process and acromion as landmarks were obtained, and then the length of the coracoacromial ligament was measured using the acoustic shadows as the index. On the same screens, the thickness at the center of the coracoacromial ligament was measured (Figure 1). This measurement was performed on the most lateral

Table 1. Demographic characteristics of the participants.

\begin{tabular}{cccc}
\hline & Normal group & Cuff tear group & P value $^{*}$ \\
\hline number/shoulder & $20 / 27$ & $15 / 19$ & Not available \\
Age, years & $41.4 \pm 22.9$ & $67.2 \pm 10.9$ & $<0.0001$ \\
Sex, male: female, $\mathrm{n}(\%)$ & $12(60): 8(40)$ & $7(47): 8(53)$ & 0.4332 \\
\hline
\end{tabular}

*Student's $t$-test for age and chi-square test for sex.

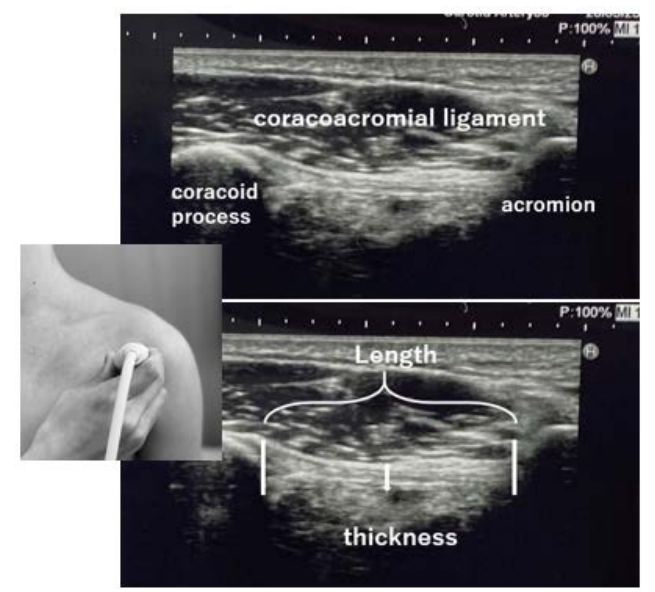

Figure 1. Measurement of the length and thickness of the coracoacromial ligament using ultrasonography. Longitudinal images of the coracoacromial ligaments with the coracoid process and acromion as landmarks are obtained, and then the length of the coracoacromial ligament is measured using the acoustic shadows as the index. On the same screens, the thickness at the center of the coracoacromial ligament is measured. 
side of the coracoacromial ligament, which is the most in contact with the rotator cuff. The values measured in the present study were almost equal to those in a previous study using the same method [7]. Thus, it is considered that this method had high reproducibility. Student's $t$-test was used to examine differences between the groups in length and thickness of the coracoacromial ligament, and significance was set at $\mathrm{P}<0.05$. The Institutional Review Board of Akita university approved the study (No1190), and informed consent was obtained from each volunteer before participation in the study.

\section{Results}

In the Normal group, the length and thickness of the coracoacromial ligament were $28.6 \pm 1.7 \mathrm{~mm}$ (mean $\pm \mathrm{SD}$ ), and $0.98 \pm 0.22 \mathrm{~mm}$, respectively. In the Cuff tear group, the length and thickness of the coracoacromial ligament were $25.9 \pm$ $2.5 \mathrm{~mm}$ and $1.04 \pm 0.24 \mathrm{~mm}$, respectively. The coracoacromial ligament of the Cuff tear group was significantly shorter than that of the Normal group $(\mathrm{P}<$ 0.0001), but there was no significant difference in the thickness of the coracoacromial ligaments between the Normal group and the Cuff tear group $(\mathrm{P}=$ 0.3906) (Table 2).

In the Young group, the length and thickness of the coracoacromial ligament were $29.2 \pm 1.8 \mathrm{~mm}$ and $0.97 \pm 0.18 \mathrm{~mm}$, respectively. In the Old group, the length and thickness of the coracoacromial ligament were $28.0 \pm 1.5 \mathrm{~mm}$ and $1.00 \pm 0.26 \mathrm{~mm}$, respectively. There were no significant differences in the length and the thickness of the coracoacromial ligaments between the Young and Old groups $(\mathrm{P}=0.0688, \mathrm{P}=0.6965)$ (Table 3 ).

There was no significant difference in age between the Old group and the Cuff tear group $(\mathrm{P}=0.3879)$, but the coracoacromial ligament of the Cuff tear group was significantly shorter than that of the Old group $(\mathrm{P}=0.0185)$ (Figure 2$)$. The lengths of the coracoacromial ligaments of males and females were $27.5 \pm 2.5$ $\mathrm{mm}$ and $27.5 \pm 2.3 \mathrm{~mm}$, respectively, and their thicknesses were $1.05 \pm 0.19 \mathrm{~mm}$

Table 2. Length and thickness of the coracoacromial ligament in the normal and cuff tear groups.

\begin{tabular}{cccc}
\hline & Normal group & Cuff tear group & P value $^{\star}$ \\
Length $(\mathrm{mm})$ & $28.6 \pm 1.7$ & $25.9 \pm 2.5$ & $<0.0001$ \\
Thickness $(\mathrm{mm})$ & $0.98 \pm 0.22$ & $1.04 \pm 0.24$ & 0.3906 \\
\hline
\end{tabular}

*Student's $t$-test.

Table 3. Length and thickness of the coracoacromial ligament in the Young and Old Groups.

\begin{tabular}{cccc}
\hline & Young group & Old group & P value $^{*}$ \\
\hline Length $(\mathrm{mm})$ & $29.2 \pm 1.8$ & $28.0 \pm 1.5$ & 0.0688 \\
Thickness $(\mathrm{mm})$ & $0.97 \pm 1.8$ & $1.00 \pm 0.26$ & 0.6965
\end{tabular}

${ }^{\star}$ Student's $t$-test. 
and $0.96 \pm 0.24 \mathrm{~mm}$, respectively. There were no significant differences in the length and thickness of the coracoacromial ligaments between the sexes $(\mathrm{P}=$ $0.9521, \mathrm{P}=0.1854)($ Table 4$)$.

\section{Discussion}

The length and thickness of the coracoacromial ligament of a living shoulder were easily evaluated with ultrasonography in the present study, and it was found that the coracoacromial ligament was significantly shorter in shoulders with a rotator cuff tear.

A rotator cuff tear is one of the most common causes of shoulder pain and restriction of shoulder range of motion in elderly persons. A rotator cuff tear is a progressive condition that does not heal spontaneously, and although the size of the tear increases with age, conservative management is the first-choice treatment. However, tears that have become very large are difficult to repair, and the postoperative clinical outcome becomes poor. Therefore, there are cases where early surgery is required. If the risk of rotator cuff tear can be evaluated quantitatively before the tear occurs, it would be very useful information when

Length of the coracoacromial ligament

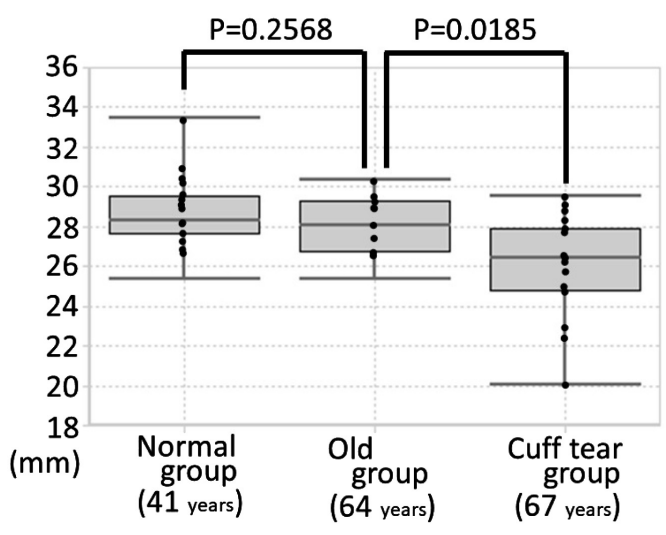

Figure 2. Differences in the length of the coracoacromial ligament with and without a rotator cuff tear. There is no significant difference in the length of the coracoacromial ligament between the Normal group and the Old group. However, the coracoacromial ligament is significantly shorter in the Cuff tear group than in the Old group, with no significant difference in age between the two groups.

Table 4. Length and thickness of the coracoacromial ligament in the male and female groups.

\begin{tabular}{cccc}
\hline & Male & Female & P value $^{*}$ \\
\hline Length $(\mathrm{mm})$ & $27.5 \pm 2.5$ & $27.5 \pm 2.3$ & 0.9521 \\
Thickness $(\mathrm{mm})$ & $1.05 \pm 0.19$ & $0.96 \pm 0.24$ & 0.1854
\end{tabular}

*Student's $t$-test. 
considering the surgical indication for subacromial decompression, especially in the case of patients who have the symptoms of subacromial impingement syndrome without a rotator cuff tear.

We have previously clarified the relationship between the elasticity of the coracoacromial ligament and rotator cuff tear by evaluating the material properties of the coracoacromial ligament [5] [6]. However, special equipment is needed to evaluate the material properties of the coracoacromial ligament; therefore, it has not been widely used clinically as an evaluation method for the risk of rotator cuff tears. Thus, the present study clarified the relationship between rotator cuff tear and the length and thickness of the coracoacromial ligament, which can be easily measured, and investigated whether they were useful indicators of the risk and progression of rotator cuff tear.

Previous reports using cadaveric shoulders showed that the length of the coracoacromial ligament was significantly shorter in the shoulder with a rotator cuff tear than in the normal shoulder, but there was no significant difference in the thickness of the coracoacromial ligament [8] [9]. In addition, the coracoacromial ligament that is composed of two or more bands is shorter than the coracoacromial ligament composed of one band, and it was reported recently that there were many rotator cuffs tears in shoulders with a short, multiple band coracoacromial ligament [10]. Based on these results, it has been considered that the short coracoacromial ligament is a risk factor for rotator cuff tear because it reduces the space under the coracoacromial arch. That is, under the same conditions, if the coracoacromial ligament is even slightly shorter than normal, the space under the coracoacromial arch becomes narrower, and the contact pressure between the rotator cuff and the coracoacromial arch becomes higher. The short coracoacromial ligament may pose a high risk of rotator cuff tear, considering that the contact pressure is applied to the rotator cuff each time the shoulder is moved.

However, these are all reports using cadaveric shoulders. Although the length and thickness of the coracoacromial ligament in living shoulders with ultrasonography have been previously evaluated, the relationship between the size of the ligament and rotator cuff tears was not clarified in that report [7]. Thus, the present study is the first to investigate the relationship between the length and thickness of the coracoacromial ligament and rotator cuff tears in the living shoulder. The coracoacromial ligament in shoulders with rotator cuff tears was significantly shorter, and this result was consistent with previous results using cadaveric shoulders. Based on these results obtained in the living shoulder, measuring the length of the coracoacromial ligament in clinical settings can be used to assess the risk for the occurrence and progression of rotator cuff tears.

One of the limitations of this study is that there was no adjustment for physique. However, it was expected that the length of the coracoacromial ligament would not differ greatly depending on the physique, because the results of this study showed no difference in the length of the coracoacromial ligament due to sex or age. The length of the coracoacromial ligament is an ideal index for the 
risk of rotator cuff tear that can be used without any complicated calculations for adjustment. In the future, it will be necessary to confirm that there is no significant difference in the length of the coracoacromial ligament due to differences in height within the same sex in order to determine whether there is a need for adjustment by physique.

With the measurement method used in the present study, the coracoacromial ligament appeared shorter in the presence of subacromial osteophytes. This is another limitation of this study. However, this is an advantage for an index to evaluate the risk of rotator cuff tear, because the greater the size of the subacromial osteophyte, the greater the risk of rotator cuff tear; thus, the risk can be evaluated simply by measuring the length of the coracoacromial ligament. It is not necessary to distinguish between the patient having a congenital short coracoacromial ligament and the patient having a ligament that was measured to be shorter because of the presence of subacromial osteophytes. When the length of the coracoacromial ligament is measured using the method of the present study in shoulders without rotator cuff tears, if it is shorter than a certain value, there is a high possibility that a rotator cuff tear will occur in the future.

It is important to note that the present study only proves that the coracoacromial ligament was shorter in the shoulder after the rotator cuff had already torn. Prospective studies are needed to clarify whether this method of measuring the length of the coracoacromial ligament will facilitate risk assessment for rotator cuff tears. This research is the first step in presenting this to a worldwide audience.

\section{Conclusion}

The morphology of the coracoacromial ligament of the living shoulder was investigated using ultrasonography. The length of the coracoacromial ligament was significantly shorter in shoulders with rotator cuff tears than in normal shoulders.

\section{Data Availability}

The data used to support the findings of this study are available from the corresponding author upon request.

\section{Funding Statement}

This research did not receive any specific grant from funding agencies in the public, commercial, or not-for-profit sectors.

\section{Conflicts of Interest}

The authors declare no conflicts of interest associated with this manuscript.

\section{References}

[1] Li, X., Xu, W., Hu, N., et al. (2017) Relationship between Acromial Morphological 
Variation and Subacromial Impingement: A Three-Dimensional Analysis. PLoS ONE, 12, e0176193. https://doi.org/10.1371/journal.pone.0176193

[2] Kaur, R., Dahuja, A., Garg, S., Bansal, K., Garg, R. and Singh, P. (2019) Correlation of Acromial Morphology in Association with Rotator Cuff Tear: A Retrospective Study. Polish Journal of Radiology, 84, 459-463. https://doi.org/10.5114/pjr.2019.90277

[3] Neer II, C.S. (1983) Impingement Lesions. Clinical Orthopaedics and Related Research, 173, 70-77. https://doi.org/10.1097/00003086-198303000-00010

[4] Yamamoto, N., Muraki, T. and Sperling, J.W. (2010) Contact between the Coracoacromial Arch and the Rotator Cuff Tendons in Nonpathologic Situations: A Cadaveric Study. Journal of Shoulder and Elbow Surgery, 19, 681-687.

[5] Kijima, H., Minagawa, H., Saijo, Y., et al. (2009) Degenerated Coracoacromial Ligament in Shoulders with Rotator Cuff Tears Shows Higher Elastic Modulus: Measurement with Scanning Acoustic Microscopy. Journal of Orthopaedic Science, 14, 62-67. https://doi.org/10.1007/s00776-008-1283-x

[6] Kijima, H., Minagawa, H., Tomioka, T., et al. (2013) Elasticity of the Coracoacromial Ligament in Live Shoulders with Rotator Cuff Tear: Measurement with Ultrasound Elastography. Surgical Science, 4, 1-5.

https://doi.org/10.4236/ss.2013.49A001

[7] Moriggl, B. (1997) Fundamentals, Possibilities and Limitations of Sonography of Osteofibrous Tunnels in the Shoulder Area. Annals of Anatomy-Anatomischer Anzeiger, 179, 375-392. https://doi.org/10.1016/S0940-9602(97)80082-9

[8] Fremerey, R., Bastian, L. and Siebert, W.E. (2000) The Coracoacromial Ligament: Anatomical and Biomechanical Properties with Respect to Age and Rotator Cuff Disease. Knee Surgery, Sports Traumatology, Arthroscopy, 8, 309-313. https://doi.org/10.1007/s001670000135

[9] Soslowsky, L.J., An, C.H., Johnston, S.P. and Carpenter, J.E. (1994) Geometric and Mechanical Properties of the Coracoacromial Ligament and Their Relationship to Rotator Cuff Disease. Clinical Orthopaedics and Related Research, 304, 10-17. https://doi.org/10.1097/00003086-199407000-00003

[10] Kesmezacar, H., Akgun, I., Ogut, T., Gokay, S. and Uzun, I. (2008) The Coracoacromial Ligament: The Morphology and Relation to Rotator Cuff Pathology. Journal of Shoulder and Elbow Surgery, 17, 182-188. 